\title{
Patient-Reported Access in the Patient-Centered Medical Home and Avoidable Hospitalizations: an Observational Analysis of the Veterans Health Administration
}

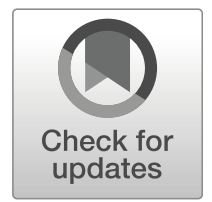

\author{
Matthew R. Augustine, MD $D^{1,2}$, Karin M. Nelson, $M D, M S H S^{3,4,5}$, \\ Stephan D. Finn, MD, MPH ${ }^{3,4}$, and Edwin S. Wong, $P H D^{4,5}$
}

'Department of Medicine, James J Peters VA Medical Center, Bronx, NY, USA; ${ }^{2}$ Department of Medicine, Icahn School of Medicine at Mount Sinai, New York, NY, USA; ${ }^{3}$ Department of Medicine, University of Washington, Seattle, WA, USA; ${ }^{4}$ Department of Health Services, University of Washington, Seattle, WA, USA; ${ }^{5}$ Center of Innovation for Veteran-Centered and Value-Driven Care, VA Puget Sound Health Care System, Seattle, WA, USA.

\begin{abstract}
BACKGROUND: The Patient-Centered Medical Home (PCMH) has emphasized timely access to primary care, often by using non-traditional modes of delivery, such as care in person after-hours or by phone during or after normal hours. Limited data exists on whether improving patient-reported access with these service types reduces hospitalization.
\end{abstract}

OBJECTIVE: To examine the association of patientreported access to primary care within the Veteran Health Administration (VHA) via five service types and hospitalizations for ambulatory care sensitive conditions (ACSCs). DESIGN: Retrospective cohort study, using multivariable logistic regression adjusting for patient demographics, comorbidity, characteristics of patients' area of residence, and clinic-level random effects.

PARTICIPANTS: A total of 69,710 VHA primary care patients who responded to the 2012 Survey of Healthcare Experiences of Patients (SHEP), PCMH module.

MAIN MEASURES: Survey questions captured patients' ability to obtain care from VHA for five service types: routine care, immediate care, after-hours care, care by phone during regular office hours, and care by phone after normal hours. Outcomes included binary measures of hospitalization for overall, acute, and chronic ACSCs in 2013, identified in VHA administrative data and Medicare feefor-service claims.

KEY RESULTS: Patients who reported "always" able to obtain after-hours care compared to "never" were less likely to be hospitalized for chronic ACSCs (OR 0.62, 95\% CI 0.44-0.89, $p=0.009$ ). Patients reporting "usually" getting care by phone during regular hours were more likely have a hospitalization for chronic ACSC (OR

Prior Presentations This work was presented as poster at the Academy Health's Annual Research meeting on June 27, 2016, in Boston, MA.

This work was also presented in an VA Health Services Research \& Development cyber seminar on December 19, 2018, which can be accessed at https://www.hsrd.research.va.gov/for_researchers/cyber_ seminars/archives/video archive.cfm?SessionID $=3572 \&$ Seriesid $=65$.

Electronic supplementary material The online version of this article (https://doi.org/10.1007/s11606-019-05060-0) contains supplementary material which is available to authorized users.

Received July 22, 2018

Revised November 27, 2018

Accepted March 27, 2019

Published online June 3, 2019
1.49, 95\% CI 1.03-2.17, $p=0.034)$. Experiences with routine care, immediate care, and care by phone after-hours demonstrated no significant association with hospitalization for ACSCs.

CONCLUSIONS: Improving patients' ability to obtain after-hours care was associated with fewer hospitalizations for chronic ACSCs, while access to care by phone during regular hours was associated with more hospitalizations. Health systems should consider the benefits, including reduced hospitalizations for chronic ACSCs, against the costs of implementing each of these PCMH services.

KEY WORDS: access to care; primary care; veterans; Health Services Research; utilization.

J Gen Intern Med 34(8):1546-53

DOI: $10.1007 / \mathrm{s} 11606-019-05060-0$

(c) Society of General Internal Medicine (This is a U.S. government work and not under copyright protection in the U.S.; foreign copyright protection may apply) 2019

\section{INTRODUCTION}

Although access to primary care is a key factor in preventing and managing disease and deterring costly acute care ${ }^{1,2}$, over $60 \%$ of Americans report difficulty obtaining care after regular business hours, and less than $30 \%$ of practices are organized with arrangements for after-hours care. ${ }^{3}$ The Patient-Centered Medical Home $(\mathrm{PCMH})$ is the leading model in primary care reorganization, aiming to introduce new service types to improve access and deliver patient-driven care. ${ }^{4-6}$ These service types include urgent and after-hours services in person or by phone. Even with broad implementation of the PCMH and adoption of these service types, the impact of expanded access within the PCMH upon downstream hospitalization remains understudied. ${ }^{7}$

Hospitalizations due to ambulatory care sensitive conditions (H-ACSCs) are potentially avoidable with timely access to appropriate primary care. ${ }^{8,9} \mathrm{H}$-ACSCs are recognized as a metric for performance and quality. ${ }^{10}$ Despite modest declines in H-ACSCs from 2005 to 2013, rates of H-ACSCs remain above national benchmarks. ${ }^{11} \mathrm{H}-\mathrm{ACSCS}$ have been associated with the availability of primary care resources ${ }^{12-16}$ and factors 
associated with limited and inequitable access - including race, ethnicity, income, neighborhood conditions, and rurality of residence. ${ }^{9}{ }^{17-23}$ Global measures of PCMH implementation, which include access, have been associated with improvement in clinical quality and reductions in H-ACSCs. ${ }^{24}$ In one study which examined the effects of access in isolation, clinics making structural changes to improve access did not demonstrate a reduction in H-ACSCs. ${ }^{25}$ However, structural changes alone may not alter patients' perceptions of access to primary care and alter health-seeking behaviors. Further, the PCMH emphasizes implementation of multiple service types, each of which may have variable effect of enhancing access and deterring the need for hospitalization.

In this study, we examined whether patient-reported access with five different PCMH-related service types modify future H-ACSCs. We used survey responses from a national sample of patients from the Veterans Health Administration (VHA). By leveraging administrative data from the VHA and claims from fee-for-service Medicare, we were distinctly able to examine the relationship between patient-reported access within the PCMH and H-ACSCs.

\section{Conceptual Framework}

We relied upon a previously developed conceptual framework, which suggests that patients' perceived access and healthcare need are major determinants of health care service use. ${ }^{26,27} \mathrm{In}$ this study, perceived access represents a patients' ability to receive primary care in a timely fashion. We hypothesized that greater perceived access to PCMH-related primary care service types would reduce the likelihood of H-ACSCs.

\section{METHODS}

\section{Data Sources}

We used data from the VHA's Survey of Healthcare Experiences of Patients, PCMH Module (SHEP-PCMH), administered between March 1, 2012, and September 30, 2012, to a random, nationally representative sample of patients with established care in the VHA. The SHEP-PCMH is adapted from the Consumer Assessment of Healthcare and Provider Systems, PCHM item set (CAHPS-PCMH) ${ }^{28}$ and was first implemented after validation ${ }^{29}$ in 2012.

We linked SHEP-PCMH data to four other data sources. Administrative data from the VHA Corporate Data Warehouse (CDW) included comprehensive clinical and demographic information, used to construct variables describing patient characteristics, comorbidity, and VHA utilization, including prior primary care use and H-ACSCs. We also ascertained non-VHA HACSCs from fee-for-service (FFS) Medicare claims data. County-level data from the 2012 Area Health Resource File were used to derive characteristics of patients' county of residence. ${ }^{30}$ Rural Urban Commuting Codes (RUCA) version 2.0 was used to identify rurality of patients' residence ZIP code. ${ }^{31}$

\section{Study Sample}

We identified 75,101 patients who responded to the SHEPPCMH, reflecting a $46 \%$ response rate. After excluding patients who did not respond to the access-related questions $(N=$ $4602)$ and patients with missing covariate data $(N=789)$, the final study sample included 69,710 patients, weighted to the VHA population who completed the nearly 10 million outpatient visits in 2012.

Explanatory Variables: Patient-Reported Access. We used responses from five questions of the SHEP-PCMH. These questions have been increasingly used as consumer-driven metrics for quality and access. ${ }^{24}$ Prior studies have identified population-level differences ${ }^{29,}{ }^{32-34}$; however, to date, the effect of patient-reported access upon hospitalization remains understudied.

These questions assessed access to care via five different PCMH-related service types: routine care, care by phone during regular hours, urgent care, after-hours care, and care by phone after-hours (Supplemental Table 1). After-hours refers to care sought during evening, weekends, or holidays. All questions referenced the patients' assigned primary care provider and assessed access in two stages. First, the patient was asked if they sought or needed the service type within the last 12 months. Patients who identified seeking or needing the service type were prompted to answer a follow-up question, eliciting how often they could obtain care: always, usually, sometimes, or never. Patients reporting not seeking or needing a service were designated in a fifth "not seeking/needing" category. We examined the relationship between experiences to each of these five services with H-ACSCs in five separate analyses.

Outcome: Potentially Avoidable Hospitalization. The primary outcome was a dichotomous measure denoting any overall H-ACSC from October 1, 2012, to September 30, 2013. ACSCs include 13 different conditions for which hospitalizations are considered potentially avoidable by adequate access to primary care services. We used standard definitions set forth by the AHRQ Quality Indicators, version $4.5^{35,36}$ and separately defined variables denoting any hospitalization due to acute and chronic ACSCs.

Covariates. We controlled for a comprehensive set of factors known to impact access to care. These included age, race/ethnicity, ${ }^{20}, 22$ marital status, and educational achievement. ${ }^{19}, 23$ Economic factors encompassed exemption from VHA copayments and the unemployment rate and poverty area designation of patients' county of residence. ${ }^{18,21,37-40}$ Geographic factors included rurality of residence $^{12,18,41}$ and distance to nearest VHA facility. ${ }^{40}$ Distance to VHA facility was calculated by straight line distance in miles from centroid ZIP code of patients' residence and assigned clinic. We classified distance into five categories: 0-4.9 miles, 5-9.9 miles, 10-19.9 miles, 20 39.9 miles, and greater than 40 miles. ${ }^{40}$ Further, we controlled 
for clinic type ${ }^{42-44}$ classified as a community-based outpatient clinic (CBOC) or VHA Medical Center. ${ }^{42,} 45$

As a measure of healthcare need, we controlled for patient comorbidity, mental health diagnoses, and prior use of primary care service. $^{26,27,46}$ The validated comorbidity risk index from Gagne et al. was derived from ICD-9 diagnoses in FY 2012. ${ }^{47,}{ }^{48}$ Behavior health diagnoses of interest to VHA and not included in risk index - depression, substance abuse, and post-traumatic stress disorder (PTSD) - were identified if patient received inpatient or outpatient ICD-9 diagnoses within the VHA in the prior 5 years. ${ }^{49-51}$ Face-to-face visits to clinics identified as primary care during the baseline year were categorized into 0 to 2 visits, 3 to 5 visits, and more than 5 visits.

Effect Modification of Routine Care Access. Given the evidence to suggest that barriers to routine care may influence need for and access to after-hours care, ${ }^{52}$ we performed post hoc analyses investigating the association of access to routine care and the need for after-hours care. Subsequently, we tested the effect modification of access to routine care upon the association of after-hours access with hospitalization for overall, acute, and chronic ACSCs. We hypothesized that poor perceived access to routine care, typically offered during the daytime, would increase the need for afterhours care, and for patients with less than optimal access to routine care, better access to after-hours care would have particularly greater impact upon hospitalizations for ACSCs.

Statistical Methods. $T$ tests and $\chi^{2}$ tests were used in bivariate analyses to compare characteristics of patients who experienced and did not experience H-ACSC. To examine the relationship between perceived access to PCMH services and H-ACSCs, we used mixed effects multivariable logistic regression with random intercepts to account for correlated clinic-level factors affecting H-ACSC. All models tested the likelihood of any hospitalization due to overall, acute, or chronic ACSC among patients reporting "not seeking/ needing" the service type and "always," "usually," and "sometimes" receiving care through service type in comparison to "never."

Effect modification was analyzed first by separate statistical models stratified by access to routine care, including populations reporting "not seeking" routine care and those who report seeking and optimally ("always") or less than optimally ("usually, sometimes, or never") receiving routine care. Subsequently, we defined access to routine care as dichotomous variable (less than optimal vs. optimal) and formally tested the interaction of less than optimal access to routine care with the four levels of perceived access to after-hours care upon any hospitalization for overall, acute, and chronic ACSC. All analyses were weighted for survey sampling to the FY2012 VHA primary care population. All analysis conducted in STATA, version 13.0 (StataCorp LP, College Station, TX). A nominal $p$ value of 0.05 was used to assess statistical hypotheses.
Sensitivity Analyses. Over $80 \%$ of VHA enrollees have at least one other form of non-VHA insurance ${ }^{53}$ and may choose to receive outpatient care outside of VHA. Except for claims data from fee-for-service Medicare, data capturing these nonVHA hospitalizations were not available. To address potential under-measurement of H-ACSCs, we conducted subgroup analysis among patients age 65 and over and were enrolled in FFS Medicare in FY2012 (Appendix). In addition, prior evidence and conceptual frameworks have highlighted the role of satisfaction in accessing and using health care services. ${ }^{26,54}$ We repeated the analyses while controlling patient-reported satisfaction with assigned provider from the SHEP-PCMH (Appendix Supplemental Tables 4.2, 4.4).

\section{RESULTS}

\section{Descriptive Statistics}

The percentage of patients who were hospitalized for overall ACSCs, acute ACSCs, and chronic ACSCs was $2.42 \%$, $0.97 \%$, and $1.57 \%$, respectively. Patients hospitalized for any ACSC were older (73.2 vs. 62.3 years) and more likely to be male $(97.1 \%$ vs. $92.6 \%)$, White ( $74.3 \%$ vs. $70.1 \%)$, and have lower educational achievement (more than high school, $46.5 \%$ vs. $59.6 \%$ ) compared patients without H-ACSC (Table 1). Patients with H-ACSC were more likely to have 5 or more primary care provider visits in the year prior to survey $(44.8 \%$ vs. $33.5 \%$ ) and higher comorbidity risk (Gagne risk score, 1.96 vs. 0.60). However, patients with H-ACSC had a lower prevalence of PTSD (14.9\% vs. $21.0 \%)$.

\section{Overall ACSCs}

In adjusted analyses, patients reporting greater access by each of the PCMH-related service types demonstrated no statistically significant difference in hospitalization due to overall ACSCs in subsequent year (Supplemental Table 3). Patients reporting "not needing," compared to patients who reported needing and "never" receiving after-hours care were less likely to be hospitalized (OR 0.56 ; CI $0.47-0.68, p<0.001$ ).

\section{Acute ACSCs}

For acute ACSCs, significant differences were observed among experiences with immediate care $(p=0.002)$ in unadjusted analysis (Supplemental Table 2); however, in adjusted analyses, greater ability to obtain PCMH-related services types was not significantly associated with hospitalizations due to acute ACSCs for any service type (Table 2, Supplemental Table 3).

\section{Chronic ACSCS}

For chronic ACSCs, in adjusted analyses, comparing to patients who reported "never" being able to receive after-hours care, those reporting "always" receiving care (OR 0.62, CI $0.44-0.89, p=0.009)$ and "not needing" care (OR 0.50, CI 
Table 1 Characteristics of Cohort With and Without Hospitalization for Ambulatory Care Sensitive Condition (H-ACSC) in 2013

\begin{tabular}{|c|c|c|c|c|}
\hline & & \multirow{2}{*}{$\begin{array}{l}\text { All* } \\
n=69,710\end{array}$} & \multirow{2}{*}{$\frac{\mathrm{H}-\mathrm{ACSC} \dagger}{n=2026}$} & \multirow{2}{*}{$\begin{array}{l}\text { No H-ACSC } \\
n=67,684\end{array}$} \\
\hline & & & & \\
\hline Age & Mean (SD) & $62.6(14.5)$ & $73.2(11.4)$ & $62.3(14.5)$ \\
\hline Sex $(\%)$ & Male & 92.7 & 97.1 & 92.6 \\
\hline Married (\%) & & 52.2 & 55.9 & 52.2 \\
\hline \multirow[t]{4}{*}{ Race $(\%)$} & White & 70.3 & 74.4 & 70.1 \\
\hline & Black & 14.6 & 12.5 & 14.7 \\
\hline & Latino/Hispanic & 7.2 & 3.3 & 7.3 \\
\hline & Other races & 7.9 & 9.8 & 7.9 \\
\hline \multirow[t]{7}{*}{ Education level (\%) } & Unknown & 1.0 & 2.1 & 1.0 \\
\hline & 8 th grade or less & 2.5 & 5.4 & 2.4 \\
\hline & Some high school & 6.4 & 13.3 & 6.2 \\
\hline & High school graduate or GED & 30.9 & 32.7 & 30.8 \\
\hline & Some college & 40.1 & 32.7 & 40.3 \\
\hline & 4 -year college graduate & 9.9 & 7.0 & 9.9 \\
\hline & More than 4-year college degree & 9.3 & 6.8 & 9.4 \\
\hline Gagne comorbidity index & Mean (SD) & $0.63(1.55)$ & $1.97(2.15)$ & $0.60(1.52)$ \\
\hline \multirow[t]{4}{*}{ Comorbidities, FY 2012 (\%) } & Heart failure & 5.6 & 24.4 & 5.2 \\
\hline & Renal failure & 7.5 & 21.1 & 7.2 \\
\hline & COPD & 16.0 & 39.5 & 15.4 \\
\hline & Complicated diabetes & 7.8 & 18.1 & 7.6 \\
\hline \multirow[t]{3}{*}{ Behavioral health diagnoses } & Depression $\$(\%)$ & 6.3 & 6.3 & 6.3 \\
\hline & Drug abuse & 2.0 & 2.0 & 2.0 \\
\hline & PTSD & 20.9 & 14.9 & 21.0 \\
\hline \multirow[t]{3}{*}{ Primary care use in $2011^{\S}(\%)$} & $0-1$ visit & 23.3 & 18.4 & 23.4 \\
\hline & $2-4$ visits & 43.0 & 36.7 & 43.1 \\
\hline & 5 or more visits & 33.7 & 44.8 & 33.5 \\
\hline Copayment status (\%) & Copay exempt & 89.2 & 89.3 & 89.2 \\
\hline Clinic type $(\%)$ & $\mathrm{CBOC}$ & 49.7 & 51.8 & 49.7 \\
\hline \multirow[t]{3}{*}{ Residence location $^{\mathrm{II}}(\%)$} & Urban & 61.4 & 59.1 & 61.5 \\
\hline & Rural & 34.6 & 37.5 & 34.5 \\
\hline & Highly rural & 2.1 & 1.9 & 2.1 \\
\hline \multirow[t]{5}{*}{ Distance to VHA facility ${ }^{\#}(\%)$} & $<5$ miles & 30.3 & 29.5 & 30.3 \\
\hline & $5-9.9$ & 25.0 & 25.3 & 25.0 \\
\hline & $10-20$ & 24.2 & 23.0 & 24.3 \\
\hline & $20-40$ & 17.6 & 19.5 & 17.6 \\
\hline & $40+$ & 2.8 & 2.7 & 2.8 \\
\hline \multirow[t]{2}{*}{ County-level economics } & Unemployment rate, mean (SD) & $9.2(2.5)$ & $9.4(2.6)$ & $9.2(2.5)$ \\
\hline & Poverty area** $(\%)$ & 20.2 & 21.3 & 20.2 \\
\hline
\end{tabular}

*Study sample includes veterans answering one of 5 access questions in the SHEP-PCMH; $+H$-ACSC, hospitalization for overall composite conditions as defined by AHRQ Quality Indicators, version 4.5; $\neq$ Elixhauser definitions; ${ }^{\xi}$ visits recorded to VHA primary care provider; ${ }^{9}$ VHA rurality definitions base upon residence ZIP code using RUCA designation; ${ }^{*}$ straight line distance from centroid ZIP code; **poverty area as defined as greater than $20 \%$ of population in county of residence living below the federal poverty level; chronic obstructive pulmonary disease (COPD); post-traumatic stress disorder (PTSD); community-based outpatient clinic (CBOC); all estimates were weighted to the FY2012 VHA primary care population

$0.40-0.63, p<0.001)$ were less likely to be hospitalized for a chronic ACSC. Conversely, patients who reported "usually" receiving care by phone during regular hours, compared to "never," were more likely to be hospitalized for a chronic ACSCs (OR 1.49; CI 1.03-2.17, $p=0.034$ ) (Fig. 1, Supplemental Table 3).

Effective Modification of Routine Access. Patients reporting greater access to routine care were less likely to report seeking or needing access after-hours (Routine care, Always vs. Never, OR 0.23 , CI $0.20-0.27, p<0.001$; Supplemental Table 5) and other service types. Among patients who report optimal access to routine care and needed after-hours care, better access after-hours care was associated with greater likelihood for hospitalization for chronic ACSCs (Usually vs. Never, OR 2.46, CI 1.29-4.71, $p=0.007$; Supplemental Table 6.2). In contrast, among those patients who reported less than optimal access to routine care, those who reported better access to after-hours care were less likely to be hospitalized (Usually vs. Never, OR 0.50 , CI $0.26-0.96 ; p=$
0.037; Supplemental Table 6.2). This association was confirmed in test of interaction (OR 0.21 , CI 0.08 0.57, $p=0.002$; Supplemental Table 6.3).

Sensitivity Analyses. Additional analyses limiting the population to patients over 65 years of age and who were enrolled in FFS Medicare confirmed our findings of an association between after-hours access and hospitalizations for chronic ACSCS (Appendix, Supplemental Tables 4.1-5). Further, associations for both after-hours care (Always vs. Never, OR 0.62 , CI $0.44-0.87, p=0.006$ ) and care by phone (Always vs. Never, OR 1.79, CI 1.15-2.77, $p=0.009$; Usually vs. Never, OR 1.77 , CI $1.77-2.69, p=0.007$ ) were similar after controlling for satisfaction with their provider (Appendix, Supplemental Table 4.2).

\section{DISCUSSION}

The PCMH expands access by offering new service types aimed at enhancing timely access to primary care beyond 
Table 2 Patient-Reported Access with 5 PCMH-Related Primary Care Services Among Patients With and Without Hospitalization for Ambulatory Care Sensitive Condition (H-ACSC)

\begin{tabular}{|c|c|c|c|c|c|}
\hline \multirow[t]{2}{*}{ Service type } & & \multirow[t]{2}{*}{ All } & \multicolumn{3}{|c|}{ H-ACSC* } \\
\hline & & & Yes & No & $\begin{array}{l}\dagger p \\
\text { value }\end{array}$ \\
\hline Routine care & $\begin{array}{l}\text { Never (\%) } \\
\text { Sometimes } \\
\text { Usually } \\
\text { Always } \\
\text { Not } \\
\text { needed }\end{array}$ & $\begin{array}{l}N= \\
67,549 \\
4.4 \\
8.7 \\
22.3 \\
42.5 \\
22.2\end{array}$ & $\begin{array}{l}N= \\
1949 \\
2.5 \\
7.6 \\
25.7 \\
40.9 \\
23.3\end{array}$ & $\begin{array}{l}N= \\
65,600 \\
4.4 \\
8.7 \\
22.2 \\
42.5 \\
22.2\end{array}$ & 0.005 \\
\hline $\begin{array}{l}\text { Care by } \\
\text { phone regular } \\
\text { hours }\end{array}$ & $\begin{array}{l}\text { Never (\%) } \\
\text { Sometimes } \\
\text { Usually } \\
\text { Always } \\
\text { Not } \\
\text { needed }\end{array}$ & $\begin{array}{l}N= \\
68,016 \\
5.5 \\
7.8 \\
13.0 \\
23.3 \\
50.4\end{array}$ & $\begin{array}{l}N= \\
1967 \\
3.8 \\
8.8 \\
14.8 \\
25.5 \\
47.1\end{array}$ & $\begin{array}{l}N= \\
66,049 \\
5.5 \\
7.8 \\
12.9 \\
23.3 \\
50.5\end{array}$ & 0.025 \\
\hline $\begin{array}{l}\text { Immediate } \\
\text { care }\end{array}$ & $\begin{array}{l}\text { Never (\%) } \\
\text { Sometimes } \\
\text { Usually } \\
\text { Always } \\
\text { Not } \\
\text { needed }\end{array}$ & $\begin{array}{l}N= \\
67,954 \\
5.0 \\
7.0 \\
11.4 \\
20.3 \\
56.3\end{array}$ & $\begin{array}{l}N= \\
1956 \\
3.8 \\
7.3 \\
13.0 \\
18.4 \\
57.4\end{array}$ & $\begin{array}{l}N= \\
65,998 \\
5.0 \\
7.0 \\
11.3 \\
20.4 \\
56.3\end{array}$ & 0.247 \\
\hline $\begin{array}{l}\text { After-hours } \\
\text { care }\end{array}$ & $\begin{array}{l}\text { Never (\%) } \\
\text { Sometimes } \\
\text { Usually } \\
\text { Always } \\
\text { Not } \\
\text { needed }\end{array}$ & $\begin{array}{l}N= \\
67,098 \\
15.5 \\
2.5 \\
2.5 \\
5.3 \\
74.2\end{array}$ & $\begin{array}{l}N= \\
1918 \\
20.8 \\
2.6 \\
4.2 \\
7.2 \\
65.3\end{array}$ & $\begin{array}{l}N= \\
65,180 \\
15.4 \\
2.5 \\
2.5 \\
5.2 \\
74.4\end{array}$ & $<0.001$ \\
\hline $\begin{array}{l}\text { Care by } \\
\text { phone after- } \\
\text { hours }\end{array}$ & $\begin{array}{l}\text { Never (\%) } \\
\text { Sometimes } \\
\text { Usually } \\
\text { Always } \\
\text { Not } \\
\text { needed }\end{array}$ & $\begin{array}{l}N= \\
67,461 \\
2.1 \\
1.3 \\
1.7 \\
3.1 \\
91.8\end{array}$ & $\begin{array}{l}N= \\
1930 \\
2.0 \\
1.8 \\
2.3 \\
3.0 \\
91.0\end{array}$ & $\begin{array}{l}N= \\
65,531 \\
2.1 \\
1.3 \\
1.7 \\
3.1 \\
91.8\end{array}$ & 0.783 \\
\hline
\end{tabular}

Questions for each service type and responses are listed in Supplemental Table 1; *hospitalization for ambulatory care sensitive condition $(\mathrm{H}$ ACSC); all the responses weighted to national VHA population in FY 2012; †Pearson chi-squared test

traditional daytime face-to-face appointments. We found that patients reporting greater access to after-hours care were less likely to be hospitalized for chronic ACSCs, which was prominent among patients who reported poor access to routine care. In contrast, we found that greater access to other new service types was not associated with hospitalizations for ACSCs. To our knowledge, this is the first study to examine the risk of future hospitalization across patient-reported experiences with five service types of the PMCH. These findings highlight the potential differential impact of each service types and add to the gaps in a growing body of literature of how the PCMH and other care models of expanded access may modify potentially avoidable, high-cost utilization.

Our results suggest that the expansion of after-hours care may help health systems meet the unmet demand for primary care and reduce hospitalizations, particularly for patients with chronic conditions. Twenty-five percent of patients reported needing primary care after-hours; however, $60 \%$ of these patients reported never being able to receive care after-hours. Increasing after-hours care may reduce the risk of hospitalization for chronic ACSCs by up to $40 \%$. After-hours care may enhance access to the timely care needed to deter disease exacerbation and subsequent need for hospitalization, especially among patients with barriers in accessing routine care. For these populations, after-hours primary care likely serves as an appropriate substitute for preventing hospitalization. On the contrary, for populations with adequate access to routine care, after-hours care appears to serve as a complement, facilitating rather than preventing hospitalization.

As health systems extend services after-hours, these divergent populations and their outcomes need to be considered. Clinic- and patient-driven factors likely influence perceived access to routine care and need for after-hours care. Clinic wait-times have been associated with satisfaction and diabetes control, a disease underlying chronic ACSCs. ${ }^{54,55}$ In these circumstances, improving timely access to daytime routine care may preclude the need for after-hours care and reduce hospitalization (Supplemental Table 5). Patients' competing needs and economic costs during regular business hours limit access to routine primary care. ${ }^{56,57}$ Particularly for lowincome populations ${ }^{58}$ and workers with restricted day time access, ${ }^{59,} 60$ extending clinic hours may help reduce unmet health needs, ${ }^{61}$ increase satisfaction, ${ }^{60}$ reduce acute care use,${ }^{58}$ and potentially mitigate inequities.

For patients seeking care by phone during regular business hours, we observed that increased access may increase hospitalization for chronic ACSCs. Within the VHA, patients' calls are handled through regional call centers and triaged by nurses. Access to telephone triage may be safe in short term, ${ }^{62}$, ${ }^{63}$ especially if clinical availability is adequate to provide timely in-person evaluation and treatment (i.e., same-day access $\left.^{64}\right)$. If in-person availability is inadequate, telephone access, as seen in nurse-led interventions, ${ }^{63,65}$ may lead to increased referral to acute care services. Additionally, improved access to telephone services decrease in-person contacts, ${ }^{63}$ which may delay early recognition of uncontrolled chronic disease.

The absence of a significant effect of the perceived access to routine care and H-ACSCs may be explained by superseding preferences for continuity or adequate access to alternative, non-VHA sources of care. In discrete choice experiments, patients valued thoroughness and continuity with their physician over timeliness or convenience. This preference was particularly pronounced for older patients with chronic diseases or new conditions of uncertain diagnoses. ${ }^{66,67}$ In addition, most VHA patients have at least one other form of nonVHA health insurance and may seek care outside the VHA. ${ }^{68}$ Alternatively, for minor conditions for which patients value timely evaluation over continuity, ${ }^{66,67,69}$ poor access to routine care may lead patients to seek care in the emergency department. ${ }^{67,70-72}$ 


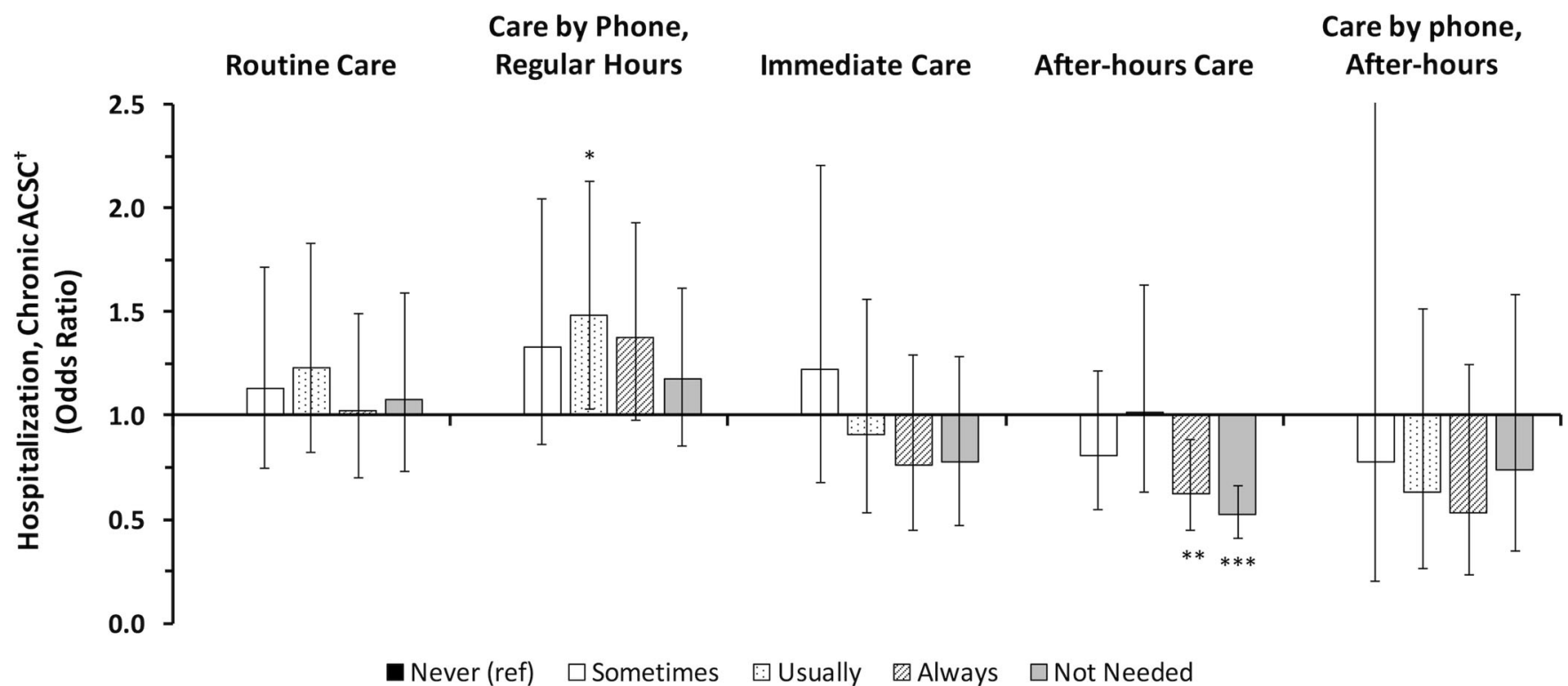

Figure 1 Association of patient-reported access to PCMH-related primary care services in 2012 and any hospitalization due to Chronic Ambulatory Care Sensitive Condition (ACSC) in 2013. $\uparrow$ Defined by AHRQ Quality Indicators, version $4.5^{36}$; columns represent multivariable logistic regression testing association with experienced access with 5 different primary care service types with hospitalization for chronic ACSCs; all models weighted to national VHA population in $2012 ; * p<0.05, * * p<0.01, * * * p<0.001$.

As the VHA and other health systems aim to expand access through the PCMH model, consideration should be given to the potential benefits and costs of implementing new service types. The implementation of some of these ways to increase access may not decrease costly utilization of acute care services and, as with phone services, may increase hospitalizations. On the contrary, improving access to after-hours care may reduce hospitalizations for ACSCs. Availability of primary care outside of traditional work hours has been historically low in the United States. ${ }^{3,73}$ Clinics with PCMH recognition were over $30 \%$ more likely to offer after-hours appointments. ${ }^{74}$ As policies are implemented and resource-limited clinics are asked to expand these services, future research should examine potential heterogeneous effects, particularly among subpopulations which may disproportionately benefit from better access. In addition, reducing H-ACSCs may not reflect appropriate care. Future studies should corroborate the benefits of after-hours care with health outcomes, including morbidity and mortality.

The study has several limitations. First, despite weighting to national VHA population, respondents and non-respondents may differ, potentially missing subpopulations with time constraints and other barriers to access. Second, patient-reported experiences with PCMH services are subject to recall bias, especially given a 12-month recall period. Third, H-ACSC measures were constructed from FFS Medicare and VHA system administrative data. Hospitalizations outside of these health programs were not measured. However, a subgroup analysis restricted to patients age 65 years and older and enrolled in FFS Medicare produced similar findings. Fourth, unmeasured confounding beyond our comprehensive set of covariates may bias relationships between the availability of primary care services and H-ACSCs.

\section{CONCLUSION}

The PCMH model encourages clinics to provide additional ways to access primary care including after traditional working hours and by phone. This study leveraged new patientreported measures capturing the availability of five different primary service types introduced as part of VHA's national implementation of PCMH. Patients who perceived greater access to after-hours care were less, while patients who experience greater access to daytime phone services were more likely to be hospitalized for chronic ACSCs. However, greater availability of these services types generally did not influence likelihood of ACSC hospitalization. With broad implementation of these services, VHA and administrators should consider the differential impact of these PCMH-related services.

Contributors/Funders: This work was undertaken as part of the Veterans Health Administration's Primary Care Analytics and Evaluation Unit, supporting and evaluating VHA's transition to a PCMH. Funding for the Primary Care Analytics and Evaluation Unit is provided by the VHA Office of Primary Care. In addition, we worked in collaboration with the VHA's Office of Performance Measurement for the use of data from the SHEP-PCMH. We thank the administrative staff and analytic teams within these organizations for their support and assistance. At the time of this research, Dr. Augustine was supported by a VHA HSR\&D Physician Advanced Fellowship and is currently supported by the Department of Medicine at James J Peters VA Medical Center and the Empire Clinical Research Investigator Program awarded through the Department of Medicine at the Icahn School of Medicine at Mount Sinai. Dr. Wong was supported by VA HSR\&D Career Development Award (CDA-13-024). 
Corresponding Author: Matthew R. Augustine, MD; Department of Medicine James $J$ Peters VA Medical Center, Bronx, NY, USA (e-mail: Matthew.Augustine2@va.gov).

Compliance with Ethical Standards:

Conflict of Interest: The authors declare that they do not have a conflict of interest.

Disclaimer: The views expressed in this paper are of the authors and do not necessarily reflect the position or policy of the United States Government, Department of Veterans Affairs, University of Washington, or Icahn School of Medicine at Mount Sinai.

\section{REFERENCES}

1. Fortney JC, Steffick DE, Burgess JF, Maciejewski ML, Petersen LA. Are primary care services a substitute or complement for specialty and inpatient services? Health Serv Res. 2005;40(5 Pt 1):1422-1442.

2. Starfield B, Shi L, Macinko J. Contribution of primary care to health systems and health. Milbank Q. 2005;83(3):457-502.

3. Schoen C, Osborn R, Squires D, Doty MM. Access, affordability, and insurance complexity are often worse in the United States compared to ten other countries. Health Affairs. 2013;32(12):2205-2215.

4. Kilo CM, Wasson JH. Practice redesign and the patient-centered medical home: history, promises, and challenges. Health Affairs. 2010;29(5):773778.

5. Jackson GL, Powers BJ, Chatterjee R, et al. Improving patient care. The patient centered medical home. A Systematic Review. Ann Intern Med. 2013;158(3): 169-178.

6. Yoon J, Chow A, Rubenstein LV. Impact of medical home implementation through evidence-based quality improvement on utilization and costs. Med Care. 2016;54(2):118-125.

7. Kehle SM, Greer N, Rutks I, Wilt T. Interventions to improve veterans' access to care: a systematic review of the literature. J Gen Intern Med. 2011;26(S2):689-696

8. Institute of Medicine (US) Committee on Monitoring Access to Personal Health Care Services, Millman M. Access to Health Care in America; 1993. https://doi.org/10.17226/2009.

9. Bindman AB, Grumbach $\mathbf{K}$, Osmond $\mathbf{D}$, et al. Preventable hospitalizations and access to health care. JAMA. 1995;274(4):305-311.

10. AHRQ QI, Version 4.5. Prevention Quality Indicators \#90, Technical Specifications, Prevention Quality Overall Composite. www. qualityindicators.ahrq.gov. Published 2013. Accessed March 5, 2017.

11. AHRQ. Potentially Avoidable Hospitalization. www.ahrq.gov. https:// www.ahrq.gov/research/findings/nhqrdr/chartbooks/carecoordination/ measure3.html. Published 2016. Accessed December 2, 2016.

12. Lin Y-H, Eberth JM, Probst JC. Ambulatory care-sensitive condition hospitalizations among medicare beneficiaries. Am J Prev Med. 2016;51(4):493-501.

13. Ansari Z, Laditka JN, Laditka SB. Access to health care and hospitalization for ambulatory care sensitive conditions. Med Care Res Rev. 2006;63(6):719-741.

14. Gibson OR, Segal L, McDermott RA. A systematic review of evidence on the association between hospitalisation for chronic disease related ambulatory care sensitive conditions and primary health care resourcing. BMC Health Serv Res. 2013;13:336.

15. Rosano A, Loha CA, Falvo R, et al. The relationship between avoidable hospitalization and accessibility to primary care: a systematic review. Eur J Public Health. 2013;23(3):356-360.

16. van Loenen T, van den Berg MJ, Westert GP, Faber MJ. Organizational aspects of primary care related to avoidable hospitalization: a systematic review. Fam Pract. 2014;31(5):502-516.

17. Oster A, Bindman AB. Emergency department visits for ambulatory care sensitive conditions: insights into preventable hospitalizations. Med Care. 2003;41(2): 198-207.

18. Schreiber S, Zielinski T. The meaning of ambulatory care sensitive admissions: urban and rural perspectives. J Rural Health. 1997;13(4):276-284.

19. Culler SD, Parchman ML, Przybylski M. Factors related to potentially preventable hospitalizations among the elderly. Med Care. 1998;36(6):804-817.

20. Will JC, Yoon PW. Preventable hospitalizations for hypertension: establishing a baseline for monitoring racial differences in rates. Prev Chronic Dis. 2013;10:120165.

21. Blustein $\mathbf{J}$, Hanson $\mathbf{K}$, Shea $\mathbf{S}$. Preventable hospitalizations and socioeconomic status. Health Aff (Millwood). 1998;17(2):177-189.
22. Pappas G, Hadden WC, Kozak LJ, Fisher GF. Potentially avoidable hospitalizations: inequalities in rates between US socioeconomic groups. Am J Public Health. 1997;87(5):811-816.

23. Bottle A, Millett C, Xie Y, Saxena S, Wachter RM, Majeed A. Quality of primary care and hospital admissions for diabetes mellitus in England. J Ambul Care Manage. 2008;31(3):226-238.

24. Nelson KM, Helfrich $\mathbf{C}$, Sun $\mathbf{H}$, et al. Implementation of the patientcentered medical home in the Veterans Health Administration: associations with patient satisfaction, quality of care, staff burnout, and hospital and emergency department use. JAMA Intern Med. 2014;174(8):13501358.

25. Yoon J, Liu C-F, Lo $\mathbf{J}$, et al. Early changes in VA medical home components and utilization. Am J Manag Care. 2015;21(3):197-204.

26. Fortney JC, Burgess JF, Bosworth HB, Booth BM, Kaboli PJ. A reconceptualization of access for 21st century healthcare. J Gen Intern Med. 2011;26 Suppl 2:639-647.

27. Rosenstock IM, Strecher VJ, Becker MH. Social learning theory and the Health Belief Model. Health Educ Q. 1988;15(2):175-183.

28. CAHPS-CG. Patient-Centered Medical Home (PCMH) Item Set. www.ahrq. gov. http://www.ahrq.gov/cahps/Surveys-Guidance/Item-Sets/PCMH/ index.html. Accessed August 23, 2016.

29. Scholle SH, Vuong O, Ding L, et al. Development of and field test results for the CAHPS PCMH Survey. Med Care. 2012;50 Suppl:S2-S10.

30. HRSA. Area Health Resources Files (AHRF). 2011 ed. Rockville, MD: Health Resources and Services Administration, Bureau of Health Workforce; 2012.

31. WWAMI Rural Health Resource Center. Rural-Urban Commuting Areas (RUCA) Data Version 2.0. 2007. http://depts.washington.edu/uwruca/ ruca-data.php.

32. Hays RD, Berman LJ, Kanter MH, et al. Evaluating the psychometric properties of the CAHPS Patient-centered Medical Home survey. Clin Ther. 2014;36(5):689-696.el.

33. Hausmann LRM, Gao S, Mor MK, Schaefer JH, Fine MJ. Understanding racial and ethnic differences in patient experiences with outpatient health care in Veterans Affairs Medical Centers. Med Care. 2013;51(6):532-539.

34. Jones AL, Mor MK, Cashy JP, et al. Racial/ethnic differences in primary care experiences in patient-centered medical homes among veterans with mental health and substance use disorders. J Gen Intern Med. 2016;31(12):1435-1443.

35. AHRQ QI, Version 4.5. Prevention Quality Indicators \#91, Technical Specfications, Prevention Quality Acute Composite. https://www. qualityindicators.ahrq.gov/Downloads/Modules/PQI/V45/TechSpecs/ PQI\%2091\%20Prevention\%20Quality\%20Acute\%20Composite.pdf. Published 2013. Accessed March 5, 2017.

36. AHRQ QI, Version 4.5. Prevention Quality Indicators \#92, Technical Specifications, Prevention Quality Chronic Composite. https://www. qualityindicators.ahrq.gov/Downloads/Modules/PQI/V45/TechSpecs/ PQI\%2092\%20Prevention\%20Quality\%20Chronic\%20Composite.pdf. Published 2013. Accessed March 5, 2017.

37. Wong ES, Hebert PL, Hernandez SE, et al. Association between local area unemployment rates and use of Veterans Affairs outpatient health services. Med Care. 2014;52(2):137-143.

38. Wong ES, Hebert PL, Nelson KM, et al. Local area unemployment and the demand for inpatient care among veterans affairs enrollees. Med Care Res Rev. 2015;72(4):468-480.

39. Poverty Areas. U S Census Bureau. https://www.census.gov/population/socdemo/statbriefs/povarea.html. Published June 1, 1995. Accessed March 1, 2016.

40. Hynes DM, Koelling $\mathbf{K}$, Stroupe $\mathbf{K}$, et al. Veterans' access to and use of Medicare and Veterans Affairs health care. Med Care. 2007;45(3):214223.

41. Veterans Health Administration. Rurality Definition and Methods Work Group Report. Office for Health for Policy and Planning. Department of Veterans Affairs; 2013.

42. Maciejewski ML, Perkins M, Li Y-F, Chapko M, Fortney JC, Liu C-F. Utilization and expenditures of veterans obtaining primary care in community clinics and VA medical centers: an observational cohort study. BMC Health Serv Res. 2007;7:56.

43. Borowsky SJ, Nelson DB, Fortney JC, Hedeen AN, Bradley JL, Chapko MK. VA community-based outpatient clinics: performance measures based on patient perceptions of care. Med Care. 2002;40(7):578-586.

44. Fortney JC, Borowsky SJ, Hedeen AN, Maciejewski ML, Chapko MK. VA community-based outpatient clinics: access and utilization performance measures. Med Care. 2002;40(7):561-569. 
45. Liu C-F, Chapko M, Bryson CL, et al. Use of outpatient care in Veterans Health Administration and Medicare among veterans receiving primary care in community-based and hospital outpatient clinics. Health Serv Res. 2010;45(5 Pt 1):1268-1286.

46. Andersen RM. Revisiting the behavioral model and access to medical care: does it matter? J Health Soc Behav. 1995;36(1):1-10.

47. Gagne JJ, Glynn RJ, Avorn J, Levin R, Schneeweiss S. A combined comorbidity score predicted mortality in elderly patients better than existing scores. J Clin Epidemiol. 2011;64(7):749-759.

48. Skinner HG, Coffey R, Jones J, Heslin KC, Moy E. The effects of multiple chronic conditions on hospitalization costs and utilization for ambulatory care sensitive conditions in the United States: a nationally representative cross-sectional study. BMC Health Serv Res. 2016;16(1):77.

49. Elixhauser A, Steiner C, Harris DR, Coffey RM. Comorbidity measures for use with administrative data. Med Care. 1998;36(1):8-27.

50. Romano PS, Roos LL, Jollis JG. Adapting a clinical comorbidity index for use with ICD-9-CM administrative data: differing perspectives. J Clin Epidemiol. 1993;46(10):1075-9 discussion1081-90.

51. Yoon J, Yano EM, Altman L, et al. Reducing costs of acute care for ambulatory care-sensitive medical conditions: the central roles of comorbid mental illness. Med Care. 2012;50(8):705-713.

52. Augustine MR, Nelson KM, Fihn SD, Wong ES. How are patients accessing primary care within the patient-centered medical home? results from the Veterans Health Administration. J Ambul Care Manage. 2018;41(3):194-203.

53. Huang G, Kim S, Gasper J, Xu Y, Bosworth T, May L. 2016 Survey of Veteran Enrollees' Health and Use of Health Care. Rockville, MD; 2017:1207.

54. Prentice JC, Davies ML, Pizer SD. Which outpatient wait-time measures are related to patient satisfaction? Am J Med Qual. 2014;29(3):227-235.

55. Prentice JC, Fincke BG, Miller DR, Pizer SD. Outpatient wait time and diabetes care quality improvement. Am J Manag Care. 2011;17(2):e43 e54.

56. Kangovi S, Barg FK, Carter T, Long JA, Shannon R, Grande D. Understanding why patients of low socioeconomic status prefer hospitals over ambulatory care. Health Affairs. 2013;32(7):1196-1203.

57. Berkowitz SA, Meigs JB, DeWalt D, et al. Material need insecurities, control of diabetes mellitus, and use of health care resources: results of the Measuring Economic Insecurity in Diabetes study. JAMA Intern Med 2015; 175(2):257-265.

58. Lowe RA, Localio AR, Schwarz DF, et al. Association between primary care practice characteristics and emergency department use in a medicaid managed care organization. Med Care. 2005;43(8):792-800.

59. Sherman BW, Gibson TB, Lynch WD, Addy C. Health care use and spending patterns vary by wage level in employer-sponsored plans. Health Affairs. 2017;36(2):250-257.

60. Cowling TE, Harris M, Majeed A. Extended opening hours and patient experience of general practice in England: multilevel regression analysis of a national patient survey. BMJ Qual Saf. 2017;26(5):360-371.
61. O'Malley AS. After-hours access to primary care practices linked with lower emergency department use and less unmet medical need. Health Affairs. 2013;32(1):175-183.

62. Campbell $\mathbf{J L}$, Fletcher $\mathbf{E}$, Britten $\mathbf{N}$, et al. Telephone triage for management of same-day consultation requests in general practice (the ESTEEM trial): a cluster-randomised controlled trial and costconsequence analysis. Lancet. 2014;384(9957):1859-1868.

63. Campbell JL, Fletcher E, Britten N, et al. The clinical effectiveness and cost-effectiveness of telephone triage for managing same-day consultation requests in general practice: a cluster randomised controlled tria comparing general practitioner-led and nurse-led management systems with usual care (the ESTEEM trial). Health Technol Assess. 2015;19(13):1-212-vii-viii.

64. Yoon J, Cordasco KM, Chow A, Rubenstein LV. The relationship between same-day access and continuity in primary care and emergency department visits. PLoS ONE. 2015;10(9):e0135274.

65. Bunn F, Byrne G, Kendall S. Telephone consultation and triage: effects on health care use and patient satisfaction. Cochrane Database Syst Rev. 2004;(4):CD004180.

66. Rubin G, Bate A, George A, Shackley P, Hall N. Preferences for access to the GP: a discrete choice experiment. Br J Gen Pract. 2006;56(531):743748.

67. Turner D, Tarrant $\mathbf{C}$, Windridge $\mathbf{K}$, et al. Do patients value continuity of care in general practice? An investigation using stated preference discrete choice experiments. J Health Serv Res Policy. 2007;12(3):132-137.

68. Ajmera M, Wilkins TL, Sambamoorthi U. Dual Medicare and Veteran Health Administration use and ambulatory care sensitive hospitalizations. J Gen Intern Med. 2011;26 Suppl 2:669-675.

69. Cheraghi-Sohi S, Hole AR, Mead N, et al. What patients want from primary care consultations: a discrete choice experiment to identify patients' priorities. Ann Fam Med. 2008;6(2):107-115.

70. Carret MLV, Fassa AG, Kawachi I. Demand for emergency health service: factors associated with inappropriate use. BMC Health Serv Res. 2007;7:131.

71. Rust G, Ye J, Baltrus P, Daniels E, Adesunloye B, Fryer GE. Practical barriers to timely primary care access: impact on adult use of emergency department services. Arch Intern Med. 2008;168(15):1705-1710.

72. Cheung PT, Wiler JL, Lowe RA, Ginde AA. National study of barriers to timely primary care and emergency department utilization among Medicaid beneficiaries. Ann Emerg Med. 2012;60(1):4-10.e2.

73. Davis $\mathbf{K}$, Stremikis $\mathbf{K}$, Squires $\mathbf{D}$, Schoen C. Mirror, mirror on the wall, 2014 update: how the us health care system compares internationally. The Commonwealth Fund; 2014.

74. Aysola J, Rhodes KV, Polsky D. Patient-centered medical homes and access to services for new primary care patients. Med Care. 2015;53(10):857-862.

Publisher's Note Springer Nature remains neutral with regard to jurisdictional claims in published maps and institutional affiliations. 